\title{
An integrative review of South African cancer nursing research published from 2002-2012
}

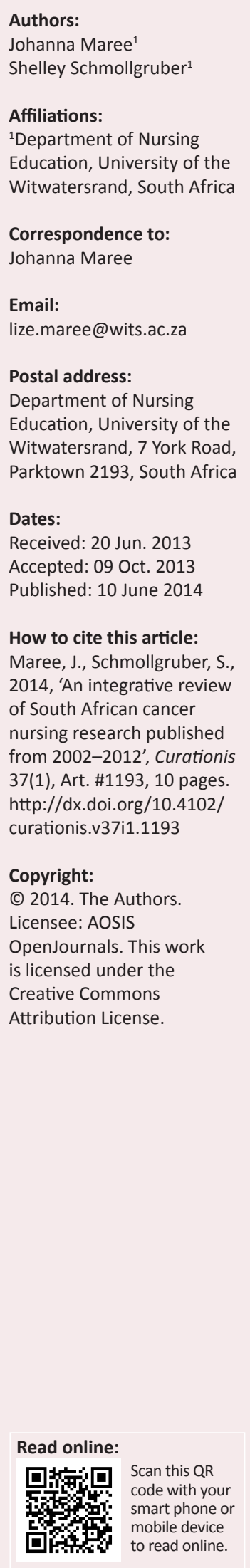

Background: This integrative review aimed to quantify the publication output of South African cancer nursing research conducted between 2002 and 2012 and to identify key trends relevant to cancer nurse researchers.

Objectives: To describe the publication output of cancer nursing research in terms of the journals of publication, authors, focus, participants and methods used, to explore whether the published work was funded and to assess the quality of the studies published.

Methods: An integrative review was conducted using the key words South Africa in combination with cancer nursing and oncology nursing to search the databases Pubmed, PsycINFO, CINAHL, Sabinet, Web of Science, Medline and OvidSP. A data extraction sheet was developed to document the required information from each paper and all publications were reviewed independently by the authors.

Results: A total of 181 publications for potential inclusion were identified and 26 papers were included in this review. Cervical cancer, specifically the prevention of this disease, was the most popular diagnostic focus and theme of investigation. Most of the studies were descriptive and none of the studies met the criteria of the highest quality.

Conclusion: Nursing added to the body of knowledge regarding the primary and secondary prevention of cancer. There is a need for work on both men and women diagnosed with the most common cancers, as well as the family and care giver. There is also a need for multidisciplinary work using complex interventions focusing on symptom management to improve patient outcomes.

\section{Introduction \\ Problem statement}

The significance of this article lies in the fact that it is the first review of South African cancer nursing research. South Africa, as a developing country, is an anomaly as it is both developed with a good infrastructure and developing, as it faces huge social and economic challenges, with a large gap between the poor dependent on developing aid and skilled professionals (Layne 1998:183). South Africa therefore faces the health challenges applicable to both the developed and developing world. In addition to primary and secondary cancer prevention, South African nursing research should be able to inform nurses practising in both the private healthcare system and the public sector, as both sectors provide patient services using sophisticated treatment (Abratt \& Vorobiof 2003:395). It is not clear how many people are diagnosed with cancer annually as the histological-based National Cancer Registry only reflects data up to 2005 (National Health Laboratory Service 2012). However, it is estimated that one in six South African men and one in seven South African women will develop cancer during their lifetime (health24 2013). According to the Cancer Association of South Africa (CANSA) (CANSA 2012), the most prevalent cancers in women are breast, cervical, unknown primary site, colorectal and uterine cancer. In men, the most prevalent are prostate, unknown primary site, lung, colorectal and oesophagus cancer. Cancer patients experience various symptoms of which pain, fatigue and nausea and vomiting seem to be the most prevalent (Maree \& Wright 2008:47).

The first National Oncology Nursing Symposium was held in 1979. During this symposium, Falkson (1979), a medical oncologist, introduced medical oncology as an established, recognised and rapidly-growing speciality and highlighted the dire shortage of oncology nurses. Nurses were asked to join the ranks of their European and American colleagues by completing the diploma in oncology nursing. Intelligence, dedication and a wish to serve humanity were required from such a nurse as it would be expected that she would become a full member of the multiprofessional healthcare team and, in many instances, act as team leader. The nature of cancer has, since this introduction, changed dramatically due to the increase in incidence, new treatments, advances in 
drugs and technologies, changing care settings and increased survival rates leading to new and varied challenges facing nurses (Mcilfatrick \& Keeney 2003:629; Pearce, Kelly \& Stevens 2001:372). In addition, the National Department of Health has, as of 1999, developed and adopted the National Cancer Control Policy which includes a cervical screening programme (CANSA 2008). Cervical screening is executed at district health level in primary health clinics (Mojaki et al. 2010:109), tasking nurses with the prevention and detection of cervical cancer. However, the nurse's role is not limited to the prevention of cervical cancer. The Scope of Practice (South African Nursing Council 1984) refers specifically to the prevention of disease and promotion of health through teaching and counselling individuals and groups and thus includes all cancers.

Nursing research not only enlarges the body of knowledge required by any profession (Keogh 1997:303), but also allows nurses to find creative and new approaches to old and new health problems and to design new and innovative programmes which will make a difference to people's health status (LoBiondo-Wood \& Haber 2010a:6). Furthermore, nursing research is an essential component for improvement of the care of people living with cancer (Mcilfatrick \& Keeney 2003:630). Despite cancer nursing being an established main nursing speciality, when looking to research to provide the evidence base for its practice, cancer nursing research is still a relatively young discipline (Molassiotis et al. 2006:432).

The cornerstone of nursing research in South Africa was laid in 1951 when the first nurse obtained a master's degree in sociology. Nursing research, however, originated in 1996 when a group of six nurses successfully completed a master's programme in nursing. Nursing research then expanded rapidly with 55 postgraduate studies completed between 1969 and 1979 and 248 studies completed between 1980 and 1990. It is not known whether oncology nursing was addressed in these studies as no mention is made of this speciality (Brink 1992). It is, however, possible that oncology nursing could have formed part of the 1.7 and $1.8 \%$ of studies focusing on the field of general nursing. In a systematic review of worldwide cancer nursing research between 1994 and 2003, Molassiotis et al. (2006:434) reported only three studies from South Africa listed by CINAHL (Cumulative Index to Nursing and Allied Health Literature), of which one was written in the English language and two in Afrikaans. In addition, infrastructure plays a major role in the progress of cancer nursing research. Quality research can only be conducted when funding is available to support research programmes (Molassiotis et al. 2006:439).

\section{Aims of the study}

South African cancer nursing research output and its characteristics have not been evaluated formally. The importance of such an evaluation resides in the identification of trends, uncovering of gaps and the provision of research directions. In addition, many cancer nurses use such findings as a guide for developing future research endeavours
(Molassiotis et al. 2006:432). Integrative review is the broadest category of review and can include both qualitative and quantitative work (LoBiondo-Wood \& Haber 2010b:212). An integrative review allowed the researchers to examine the literature using a particular lens defined by the objectives of the study to examine critically and evaluate the previous research, provide a clear account of the body of work on the subject and to arrive at specific conclusions (Molassiotis et al. 2006:431). The aim of this integrative review was to quantify the publication output related to South African cancer nursing research conducted between 2002 and 2012 and to identify key trends relevant to cancer nurse researchers. The objectives of the study were to:

- describe the publication output of cancer nursing research in terms of the journals of publication, authors, focus, participants and methods used

- explore whether the published work was funded

- assess the quality of the studies published.

\section{Research method and design Literature review}

A review was conducted of the papers published between the years 2002 and 2012. Publications qualifying for inclusion had to be peer reviewed, conducted in a South African setting and co-authored by a South African nurse. The key words South Africa in combination with cancer nursing and oncology nursing were used. The data bases searched were Pubmed, PsycINFO, CINAHL, Sabinet, Web of Science, Medline and OvidSP.

\section{Research approach and design}

Data gathering commenced in April 2012 and regular searches were carried out until April 2013 in order to identify any new studies published, adding them to the main body of the current review. A data-extraction sheet was developed so as to document the required information from each paper including the year of publication, the journal of publication, the authors, affiliation of the authors, title of the study, participants and research methods used. Funding, a key word indicating the focus of the study and four sections dedicated to the judgement of the quality of the papers were also included.

\section{Grade I studies}

In order to benchmark the quality of the South African quantitative and qualitative publications against international trends, the same grading system applied by Molassiotis et al. (2006) in the worldwide review of cancer nursing research was used. Quantitative research was assessed by means of the three-point grading system developed by Mann (Molassiotis et al. 2006:433), where Grade I refers to randomised controlled trials. Grade I studies are divided into:

- Grade IA, referring to a randomised controlled trial where the sample size has been calculated and an accurate, standard definition of outcome variables is provided. 
- Grade IB, providing only the standard definition of outcome variables .

- Grade IC, which does not include the above criteria.

\section{Grade II studies}

Grade II studies refer to prospective studies with a comparison group such as a non-randomised trial or good observational studies or retrospective studies with controls clarifying confounding variables. Grade II studies are divided into:

- Grade IIA, where the sample size has been calculated and an accurate standard definition of outcome variables and adjustment for the effects of important variables are included.

- Grade IIB studies, having at least one of the criteria of a Grade IIA study.

\section{Grade III studies}

All other studies are Grade III with:

- Grade IIIA containing a comparison group, calculated sample size and accurate standard definition of outcome variables.

- Grade IIIB studies including at least one of the criteria of Grade IIIA.

- Grade IIIC studies, which do not include any of the above criteria.

\section{Rating system}

The rating system developed by Cesario, Morin \& SantaDonato (2002:711) was used to assess the qualitative studies. Five categories applied:

- descriptive vividness

- methodological congruence with subcategories (1) rigour in documentation, (2) procedure and (3) ethics and confirmability

- analytical preciseness

- theoretical connectedness

- heuristic relevance with subcategories intuitive recognition, relationship to the existing body of knowledge and applicability.

A scoring scale of 0 to 3 was used in order to evaluate whether the different criteria were met, with $0=$ no evidence, $1=$ poor evidence, 2 = fair evidence and $3=$ good evidence. The final quality of papers was based on the total scores of each of the categories, with QI referring to good quality studies meeting $75 \%$ to $100 \%$ of the total criteria (total score of 22.5 to 30 ); QII referring to studies of fair quality meeting $50 \%$ to $74 \%$ of the total criteria (score of 15 to 22.4); and QIII referring to poorquality studies where less than $50 \%$ of the criteria were met (less than a total score of 15).

\section{Assessment of quality}

To assess the quality of the mixed-methods study, the criteria outlined by O'Cathain, Murphy \& Nicholl (2008) were used and six categories, each containing specific criteria, were assessed. The categories are the:

- success of the study

- mixed-methods design
- qualitative component

- quantitative component

- integration

- inferences made.

Stake's instrument for assessing the quality of case reports as outlined by Crowe et al. (2011) was used to evaluate the quality of the case studies. This instrument contains 20 criteria, including the readability of the report, conceptual structure, definition and description of the case, attention paid to the various contexts, presentation of the raw data and possible risks to the individual. A scoring system of yes = 2 ; yes, but $=1$; no OR not enough information $=0$ applied (O'Cathain et al. 2008) to both the mixed methods and case study. Where the appropriate answer was no, no = 2; no, but $=1$ and yes $=0$. The final quality of the studies was based on the total scores of each of the categories or criteria for the case study, with good-quality studies (QI) meeting at least 75\% of the total criteria, fair-quality studies (QII) meeting between $50 \%$ and $74 \%$ of the total criteria and poor-quality studies (QIII) less than 50\%.

\section{Data analysis}

Content analyses (Burns \& Grove 2010:528) were used to identify categories according to the focus of the study and to group the categories into themes.

All publications identified during the searches were reviewed independently by the authors. Both authors received formal training in the management, assessment and review of information and conducting reviews. Disagreements were resolved by means of discussion. A senior nurse researcher, not involved in the study, had the role of arbitrator in case of disagreement. Lists of publications obtained from the databases were first reviewed to exclude literature reviews, letters to the editor, editorials, clinical reports, dissertations, work published in non-accredited South African journals, discussion papers, comments on research published and grey literature. Only the output of published research was captured.

Abstracts of all papers not excluded were obtained and titles were first reviewed to determine whether some aspect of cancer was the focus of the study; the abstracts were used where titles did not provide clear answers. Thereafter, fulltext papers were used to review the study using the dataextraction sheet.

\section{Results}

A total of 181 publications for potential inclusion in this review were identified. Most (73) were found in Sabinet, 27 in Pubmed, 31 in Web of Science, 21 in CINAHL, 15 in PsycINFO, 14 in Medline and none in OVIDSP (list available on request). All publications identified were written in the English language. Of the 181 publications, 155 were excluded as they either did not meet the inclusion criteria or were duplicated. Twenty-six papers were included in this review (Addendum 1); only two papers (7.7\%) were 
published between 2002 and 2006, whilst 24 (92.3\%) were published between 2007 and 2012 (Figure 1). This equates to 1.95 publications per million of the population based on a population of 50.586 million (South African Statistics 2012) and 0.47 per thousand people diagnosed with cancer during 2002 to 2012 estimated according to the National Cancer Registry data (National Health Laboratory Service 2012).

Papers were published in nine journals including journals dedicated to nursing and midwifery issues in general, subject-specific journals as well as journals with a multiprofessional focus. Most papers (65.4\%) were published in journals focusing on research conducted in the South African and African context with two journals publishing $50 \%$ of the papers. However, $23.1 \%$ of the papers were published in international journals specifically dedicated to cancer. The year 2007 seems to be a defining moment as the first paper co-authored by South African nurses was published outside the borders of Africa, with a further eight published up to 2012 (Table 1).

It was difficult to evaluate the impact factor of the journals selected for the publication of the work as journals reported their impact using different assessment measures. However, $25.9 \%$ of studies were published in journals with a 2011 impact factor ranging from 1.171 to 1.410 , whilst $22.2 \%$ of the

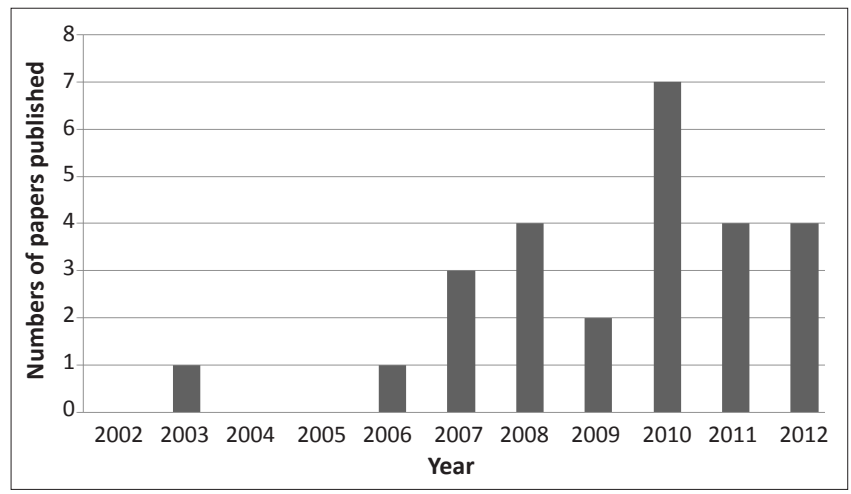

FIGURE 1: Cancer nursing research papers published between 2002 and 2012. studies were published in journals having a 2011 SCImago Journal Rank ranging from 0.13 to 0.21 (European Journal of Cancer Care 2013; European Journal of Oncology Nursing 2013; SCImago, 2007-2013).

Most of the studies (42.3\%) were conducted in a community setting; only $26.9 \%$ of the studies settings included cancer wards and cancer clinics (Table 2). The participants were primarily female as $50 \%$ of the studies targeted women. Nurses comprised the second most-studied group (19.2\%), followed by people of both genders $(11.5 \%)$. Less than a third $(30.8 \%)$ of the participants were people suffering from cancer. It seems that the families of people diagnosed with cancer were not investigated at all, as no evidence could be found (Table 3).

Only one study (3.8\%) resulted from collaborative research between researchers from South Africa and other countries, namely Sweden and the UK; the rest $(96.2 \%)$ were written by authors affiliated with South African institutions, mainly universities. Authors not affiliated to universities contributed to one $(3.8 \%)$ of the papers and represented CANSA and the South African Database for Functional Medicine. South African inter-university collaboration resulted in the publication of six papers $(23.1 \%)$. Thirty-seven South African authors contributed to the papers with $33(89.2 \%)$ contributing to only one paper; three authors contributed to two papers, one to three, one to 10 and one to 16 . Evidence of multi-disciplinary team research could not be found.

When investigating the diagnostic focus of the papers it was found that the majority of papers (53.8\%) focused on cervical cancer whilst $34.6 \%$ focused on cancer in general, $11.5 \%$ on breast cancer and $3.8 \%$ on oral cancer. A comparison between the number of papers and prevalence of the specific cancers investigated is presented in Figure 2.

Studies investigated four themes, primary and secondary prevention of cancer $(46.2 \%)$, cancer care $(26.9 \%)$, nurses and nursing practice $(15.4 \%)$ and experiencing the signs of cancer $(11.5 \%)$. No evidence of work on symptom management could

TABLE 1: Journals publishing cancer nursing papers, authored/co-authored by South African nurses between 2002 and 2012.

\begin{tabular}{|c|c|c|c|c|}
\hline Name of journal & Scope of journal & Focus of journal & $\begin{array}{l}\text { Number of papers } \\
\text { published }\end{array}$ & Year of publication \\
\hline Health SA Gesondheid & $\begin{array}{l}\text { Interdisciplinary, issues pertaining } \\
\text { to public health }\end{array}$ & $\begin{array}{l}\text { Africa and other developing countries } \\
\text { (Health SA Gesondheid, 2013) }\end{array}$ & 7 & $\begin{array}{l}2003,2007,2008,2010, \\
2011(2), 2012\end{array}$ \\
\hline Africa Journal of Nursing and Midwifery & Nursing and health-related issues & $\begin{array}{l}\text { Africa (Africa Journal of Nursing and } \\
\text { Widwifery, 2012) }\end{array}$ & 6 & $\begin{array}{l}2006,2009,2010(3) \\
2012\end{array}$ \\
\hline Journal of Research in Nursing & Nursing topics and themes & $\begin{array}{l}\text { Global (Journal of Research in Nursing, } \\
\text { 2013) }\end{array}$ & 1 & 2007 \\
\hline Curationis & Nursing and midwifery & Africa (Curationis, 2013) & 3 & 2007, 2008, 2009 \\
\hline Reproductive Health Matters & $\begin{array}{l}\text { Multi-professional, focusing on } \\
\text { women's reproductive health needs }\end{array}$ & $\begin{array}{l}\text { International (Reproductive Health } \\
\text { Matters, 2013) }\end{array}$ & 1 & 2008 \\
\hline Journal of Pain Management & $\begin{array}{l}\text { Multidisciplinary, focusing on acute, } \\
\text { chronic or cancer-related pain }\end{array}$ & $\begin{array}{l}\text { International (Journal of Pain } \\
\text { Management, 2013) }\end{array}$ & 1 & 2010 \\
\hline European Journal of Oncology Nursing & $\begin{array}{l}\text { Oncology nursing, patient care, nurse } \\
\text { education, management and policy } \\
\text { development }\end{array}$ & $\begin{array}{l}\text { International (European Journal of } \\
\text { Oncology Nursing, 2013) }\end{array}$ & 3 & $2010(2), 2011$ \\
\hline European Journal of Cancer Care & Multi-professional cancer care & $\begin{array}{l}\text { Europe and international (European } \\
\text { Journal of Cancer Care, 2013) }\end{array}$ & 3 & $2011,2012(2)$ \\
\hline
\end{tabular}


be found and no study investigated any aspect of the family or the care-giver. A detailed description is provided in Table 4.

A variety of research designs were used and nine $(34.6 \%)$ of the studies were qualitative; a further nine (34.6\%) were surveys and two $(7.7 \%)$ were pilot studies. Each of the remaining six studies used a different research design. A total of 30 samples were selected as two studies selected two samples and one study three.

A non-probability sampling approach was used for the selection of most of the samples (50\%) whilst $7.7 \%$ used a

TABLE 2: Settings and sources of information for studies included in this review $\dagger$

\begin{tabular}{lcc}
\hline Setting & $\boldsymbol{n}$ & $\mathbf{\%}$ \\
\hline Cancer care settings (hospital ward and outpatient clinic) & 7 & 26.9 \\
Surgical clinic and hospital ward & 1 & 3.8 \\
Places in the community & 11 & 42.3 \\
Clinics (primary health and other) & 3 & 11.5 \\
Records & 2 & 7.7 \\
University & 3 & 11.5 \\
Unknown & 1 & 3.8 \\
\hline
\end{tabular}

$\dagger$, Some studies used more than one setting and/or source of information and therefore percentages are higher than $100 \%$.

TABLE 3: Participants in the studies included in this review

\begin{tabular}{llcc}
\hline Participants & Subgroups & $n$ & $\%$ \\
\hline Women & From the community & 8 & 30.8 \\
& With cervical cancer & 2 & 7.7 \\
& With breast cancer & 3 & 11.5 \\
Nurses & & 5 & 19.2 \\
Both men and women & From the community & 1 & 3.8 \\
& Receiving chemotherapy & 1 & 3.8 \\
Traditional healers & With advanced cancer & 1 & 3.8 \\
Private medical practitioners & & 1 & 3.8 \\
Informal care givers & & 1 & 3.8 \\
Men from the community & & 1 & 3.8 \\
Children with cancer & & 1 & 3.8 \\
\hline
\end{tabular}

$\dagger$, Some studies targeted more than one population and therefore percentages are highe than $100 \%$

TABLE 4: Themes investigated between 2002 and 2012 in papers included in this review.

\begin{tabular}{lll}
\hline Research themes & $\boldsymbol{n}$ & $\mathbf{\%}$ \\
\hline Primary and secondary prevention of cancer & 1 & 3.8 \\
Cancer in general & 9 & 34.6 \\
Cervical cancer & 1 & 3.8 \\
Breast cancer & 1 & 3.8 \\
Oral cancer & & \\
Experiencing the signs of cancer & 1 & 3.8 \\
Breast cancer & 2 & 7.7 \\
Cervical cancer & & \\
Cancer care & 2 & 7.7 \\
Cervical cancer & 1 & 3.8 \\
Breast cancer-related lymphoedema & 1 & 3.8 \\
Needs of children & 2 & 7.7 \\
Symptoms & 1 & 3.8 \\
End of life care & & \\
Nurses and nursing practice & 2 & 7.7 \\
Knowledge and practices relating to pain & 1 & 3.8 \\
Perceptions of the cervical screening programme & 1 & 3.8 \\
Experiential world of the oncology nurse & & \\
\hline
\end{tabular}

probability sampling and $19.2 \%$ did not state which approach was used. Sample sizes varied from one to 980 participants. The mean sample size for quantitative work was 228 and for qualitative work 13. Interviews were the most common method of collecting data and were used in $73.1 \%$ of the studies. Focus groups were used in $15.4 \%$ of the studies and questionnaires in $11.5 \%$. The details of the research methods used in the studies are outlined in Table 5.

Nine studies (32.1\%) reported funding; seven $(26.9 \%)$ were funded by a local university, one $(3.8 \%)$ was funded by CANSA and one study (3.8\%) was funded by a university

TABLE 5: Research methods used in the studies included in the review.

\begin{tabular}{|c|c|c|c|}
\hline Design & Method & $n$ & $\%$ \\
\hline \multirow[t]{3}{*}{ Qualitative } & Descriptive & 6 & 21.4 \\
\hline & Phenomenological & 2 & 7.7 \\
\hline & Ethno-nursing & 1 & 3.8 \\
\hline Survey & & 9 & 34.6 \\
\hline Case study & & 1 & 3.8 \\
\hline Mixed methods & & 1 & 3.8 \\
\hline Quantitative testing of intervention & & 1 & 3.8 \\
\hline Q method & & 1 & 3.8 \\
\hline Descriptive & & 1 & 3.8 \\
\hline Formative evaluation & & 1 & 3.8 \\
\hline Pilot & & 2 & 7.7 \\
\hline \multicolumn{4}{|l|}{ Sampling $\dagger$} \\
\hline Probability & Random & 2 & 7.7 \\
\hline \multirow[t]{4}{*}{ Non-probability } & Purposive & 6 & 23.1 \\
\hline & Convenience & 14 & 53.8 \\
\hline & Snowball & 2 & 7.7 \\
\hline & Single case & 1 & 3.8 \\
\hline Not stated & & 5 & 19.2 \\
\hline \multicolumn{4}{|l|}{ Data collection methods ${ }^{\dagger}$} \\
\hline Interviews & & 19 & 73.1 \\
\hline Focus group & & 4 & 15.4 \\
\hline Questionnaires & & 3 & 11.5 \\
\hline Record review & & 3 & 11.5 \\
\hline Observation & & 1 & 3.8 \\
\hline Photographs & & 1 & 3.8 \\
\hline
\end{tabular}

$\dagger$, Some studies used more than one sampling and data collection method and therefore percentages are higher than $100 \%$

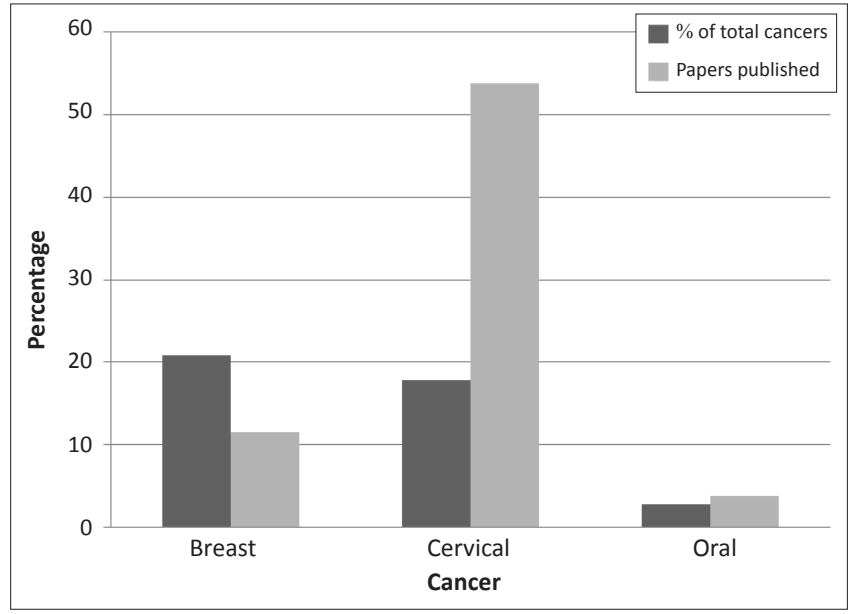

FIGURE 2: Percentage of papers published focusing on a specific cance compared to the prevalence of cancer in South Africa as indicated in the 2005 National Cancer Registry. 
TABLE 6: The quality of the studies included in this review.

\begin{tabular}{lcc}
\hline Quantitative studies & $\boldsymbol{n}$ & $\mathbf{\%}$ \\
\hline IA & 0 & 0 \\
IB & 0 & 0 \\
IC & 0 & 0 \\
IIA & 0 & 0 \\
IIB & 0 & 0 \\
IIIA & 0 & 0 \\
IIIB & 15 & 57.7 \\
IIIC & 0 & 0 \\
Qualitative studies & & \\
QI (Good) & 0 & 0 \\
QII (Fair) & 6 & 23.1 \\
QIII (Poor) & 2 & 7.7 \\
Mixed-method study & & \\
QI (Good) & 0 & 0 \\
QII (Fair) & 1 & 3.8 \\
QIII (Poor) & 1 & 3.8 \\
Case study & & \\
QI (Good) & 1 & 3.8 \\
QII (Fair) & 0 & 0 \\
QIII (Poor) & 0 & 0 \\
\hline & & \\
\hline
\end{tabular}

in the UK and the Swedish Children's Cancer Foundation. As indicated in Table 6, most studies (96.2\%) did not meet the criteria to be regarded as good quality. Quantitative studies were either descriptive or surveys and no evidence could be found of any study using a calculated sample size, comparison group and control group. However, all studies included clear definitions of outcome variables. The quality of the qualitative work seemed to be better as $77.8 \%$ of the studies met at least $50 \%$ of the evaluation criteria to be regarded as fair quality. Theoretical connectedness and procedural rigour scored the lowest with relationship to the existing body of knowledge and intuitive recognition the highest. The quality of the studies is depicted in Table 6.

\section{Discussion}

This study is the first assessment of South African cancer nursing research to date. The study provided evidence that 26 papers focusing on cancer nursing were published over a period of 10 years. When comparing the annual output reported in the current review with the output of other countries included in the worldwide review (Molassiotis et al. 2006), South Africa would be fifth in terms of the total number of work, published slightly more than Australia (2.4 papers per year) and less than Canada (4.6 per year). In terms of the number of publications per million of the population, South Africa is on a par with the UK, publishing 1.9 papers per million of the population. However, it should be remembered that eight years have passed since the world review and it would be interesting to see how South Africa performs in the next world review.

Whether the publication of 2.6 articles per year is commendable is debatable. It seems as if this review was the first assessing research output in any specialist field of nursing in South Africa. Country reviews of cancer nursing also seem to be unavailable and not having comparators complicates definite conclusions. When comparing the number of papers included in this review to the total of three included in the worldwide review (Molassiotis et al. 2006:434), it would be quite reasonable to say that oncology nursing research has progressed since the international review. In contrast, when considering the number of public and private cancer care providers, supportive and palliative care services rendered by CANSA, the Hospice and Palliative Association of South Africa and other non-governmental organisations where cancer nurses practise, the research output cannot be justified. It was primarily community members without cancer who were investigated and no evidence of nursing's attempt to improve the outcomes of patients receiving anticancer treatment could be found.

The finding that less than a third of the studies were funded and that the academic institutions were the primary funders was not surprising. Cancer and subsequently cancer research is not a national priority and the Medical Research Council and other stake holders awards 'extremely low funding' to cancer research (Albrecht 2006:36). It would, however, be interesting to determine whether primary investigators not reporting funding approached funders like CANSA, the Medical Research Council, National Research Foundation and Technology and Human Resources for Industry Programme applied for financial support and what the outcomes of such applications were. Funding reported in this review compared negatively with world trends, where $48.8 \%$ of the total $(n=619)$ reported funding (Molassiotis et al. 2006:434).

What is of great concern is finding that the majority of authors contributed to only a single paper. Cancer nursing research therefore seems to be a mere 'fact-finding' academic exercise not directed toward improving the health outcomes of communities and patients living with cancer, their caregivers and their families. Conducting small-scale research as part of a postgraduate degree in all probability adds to this situation. In addition, no author was affiliated with a clinical setting and almost all the work derived from academic settings. This is also of great concern and questions the development of cancer nursing as specialist field in the past 10 years as research forms the basis of the development of nursing (Retsas 2000:599). Holyoake (2011) is of the opinion that the gap between the nursing 'elite' and everyday majority is wider than ever. However, Molassiotis et al.(2006:438), finding a similar trend in the world review, are pragmatic about this reality and are of the opinion that this might change with joint posts between the academic and clinical settings - something yet to be implemented in South Africa.

Similarly to the work included in the world review, the diagnostic focus of the research seemed inconsistent to the disease profile. Where the focus of international studies was generic issues of patients with mixed diagnosis (Molassiotis et al. 2006), cervical cancer was the diagnostic focus of the 
majority of the South African work. Breast cancer as the most common cancer in females (National Health Laboratory Service 2012) received only limited exposure. Cervical cancer is, however, the most common cancer in Black women (National Health Laboratory Service 2012) and a preventable disease. In addition, the National Department of Health has been focusing on the prevention of cervical cancer with the screening programme introduced in 2000 (Department of Health 2000). The screening programme has not achieved the desired outcome due to low screening uptake (Gakidou, Nordhagen \& Obermeyer 2008), adding to the disease's high mortality rate of nearly 60\% (Denny 2010:71). Preventing cervical cancer remains a challenge and it thus seems quite reasonable to focus on this disease.

There is an absence of work focusing on prevalent cancers in men (such as prostate and bladder cancer) and prevalent cancers affecting both men and women (such as cancer of an unknown primary, oesophageal, colorectal and lung cancer, melanoma and Kaposi sarcoma). Similarly to breast cancer, childhood cancers received minimal exposure and lacked focus by including children with a range of diagnosis. Although childhood cancer is a rare disease affecting approximately 800 to 1500 children annually (CANSA 2013), this field of specialist nursing warrants nursing research. Work focusing on haematological cancers was also absent and, as non-Hodgkin's lymphoma is one of the most prevalent cancers in both men and women (CANSA 2012), this needs to be investigated.

Primary and secondary prevention of cancer was the focus of nearly half of the work resulting in community members being the majority of the participants. This trend does not concur with world trends where nurses and other health professionals were the participants in half of the studies and nursing issues and nursing roles the most common research focus (Molassiotis et al. 2006:436). It seems as if South African nurses, in terms of the prevention and early detection of cancer, have no role concerns or confusion as suggested in the world review.

The same disappointing trend in terms of the absence of multi-disciplinary work reported in the world review (Molassiotis et al. 2006:438) was found in this review. According to Richardson (2004:299), professional isolationism is not conducive to positive patient outcomes and mutual partnerships, valuing and shared working are the only way of improving cancer care. Research should be conducted using a team approach, involving researchers from a range of disciplines who can investigate problems from diverse perspectives and using a range of methodological approaches.

The majority of the work (two out of three studies) was quantitative, with surveys and descriptive designs being the most popular. More complicated research designs were only used in a minority of studies. Most of the qualitative work was descriptive. Both the quantitative and qualitative studies did not receive high scores in terms of quality. The quality of the qualitative work was better than the quantitative work. A similar trend was found in the international review. However, international quantitative work included approximately $10 \%$ good and $10 \%$ fair quality papers, but a higher percentage of poor quality qualitative work as compared with this review.

\section{Limitations}

It is possible that the key words used in this review may be a limitation as it could have excluded nurse-led work not appearing in the literature research under the keyword 'nursing'. In addition, international collaborative work could also have been excluded if 'South Africa' was not included in the key words. Despite these limitations, it is still believed that the article provides a fair representation of cancer nursing research conducted in South Africa as the review covers the three South African-based journals publishing nursing research.

\section{Conclusions and recommendations}

Nursing added to the body of knowledge of the primary and secondary prevention of cancer. It seems as if the research investigating this field of cancer care has reached maturity and there is thus an urgent need for more innovative and influential work to find effective solutions to the identified problems.

There is a gap in terms of research focusing on the patient diagnosed with cancer, the family and care-giver. More studies are needed on the most prevalent cancers like prostate and breast cancer and cancer of an unknown primary site. Work on haematological and cancer in children and adolescents are also needed. To join the international drive toward evidencebased practice, symptom management using complex interventions should be the priority of nurses practising in cancer care settings. This should preferably be done in a programmatic way in collaboration with other members of the multidisciplinary team to ensure that patient problems are addressed in a holistic culturally-sensitive manner. A need for work on symptoms like breathlessness, fatigue, cachexia and depression has been identified internationally (Molassiotis et al. 2006:439). However, pain remains an unrelieved symptom of South African cancer patients (Maree \& Wright 2008:45), therefore pain management also needs urgent attention. Unique to developing countries is the high prevalence of cervical cancer and problems related to this disease and its treatment, such as sexual functioning and vaginal stenosis, should also be addressed.

Lack of infrastructure will continue to hamper the progression of cancer nursing research and nurses should be empowered to apply for research grants. Lastly, it is essential to combine our efforts with international expertise to build on current evidence to find tailor-made solutions to the problems unique to people living with cancer in a developing country, their caregivers and families.

\section{Acknowledgements}

The authors would like to express their appreciation to Prof Alex Molassiotis, Honorary Professor in the Department of 
Nursing Education at the University of the Witwatersrand, for his guidance and support with conducting of this review.

\section{Competing interests}

The authors declare that they have no financial or personal relationships which may have inappropriately influenced them in writing this article.

\section{Authors' contributions}

J.M. (University of the Witwatersrand) was the project leader and wrote the manuscript. S.S. (University of the Witwatersrand) reviewed the manuscript. Both authors reviewed the publications identified during the searches.

\section{References}

Abratt, R.P. \& Vorobiof, D.A., 2003, 'Cancer in Africa', The Lancet Oncology, 4(7), $394-$ 396. http://dx.doi.org/10.1016/S1470-2045(03)01135-5

Africa Journal of Nursing and Widwifery, 2012, 'Scope of the publication', viewed 2 February 2013, from http://www.journals.co.za/ej/ejour ajnm.html

Albrecht, C., 2006, 'Overview of the South African cancer research environment as a basis for discussions concerning the activation of CARISA (Cancer Research Initiative of South Africa)', viewed 16 November 2013, from http://www. sahealthinfo.org/cancer/overviewdocument.pdf

Brink, H., 1992, 'The status of nursing research in the Republic of South Africa: past and present perspectives', Curationis, 15(4), 28-31. http://dx.doi.org/10.4102/ curationis.v15i4.375, PMid:1301313

Burns, N. \& Grove, S, 2010, The practice of nursing research: appraisal, synthesis, and generation of evidence, 6th edn., Saunders, St Louis.

CANSA, 2008, 'Position statement on cancer of the cervix', viewed 16 November 2013, from http://www.cansa.org.za/files/2013/08/Position-Statement-CervicalCancer-July-2013.pdf

CANSA, 2012, 'South African cancer statistics', viewed 9 February 2013, from http:// www.cansa.org.za/statistics/

CANSA, 2013, 'Warning signs - childhood cancer',viewed 16 November 2013, from http://www.cansa.org.za/warning-signs-childhood-cancers/

Cesario, S., Morin, K. \& Santa-Donato, A., 2002, 'Evaluating the level of evidence of qualitative research', Journal of Obstetric, Gynecologic, \& Neonatal Nursing, 31(6) 708-714. PMid:12465867

Crowe, S., Cresswell, K., Robertson, A., Huby, G., Avery, A. \& Sheikh, A, 2011, 'The case study approach', BMC Medical Research Methodology, 11(1), 100. http://dx.doi. org/10.1186/1471-2288-11-100, PMid:21707982, PMCid:PMC3141799

Curationis, 2013, 'Focus and scope' viewed 4 February 2013, from http://www. curationis.org.za/index.php/curationis/pages/view/about

Denny, L, 2010, 'Cervical cancer in South Africa: an overview of current status and prevention strategies', Continuing Medical Education, 28(2), 70-73.

Department of Health, 2000, National guidelines for cervical cancer screening programme, Government Printers, Pretoria.

Enskär, K., Ljusegren, G., Berglund, G., Eaton, N., Harding, R., Mokoena, J., et al 2007 'Attitudes to and knowledge about pain and pain management, of nurses 2007 , 'Attitudes to and knowledge about pain and pain management, of nurses
working with children with cancer: A comparative study between UK, South Africa working with children with cancer: A comparative study between UK, South Africa
and Sweden', Journal of Research in Nursing, 12(5), 501-515. http://dx.doi. and Sweden', Journal of Research
org/10.1177/1744987107080455

European Journal of Cancer Care, 2013, 'Aims and scope of the journal', viewed 4 February 2013, from http://onlinelibrary.wiley.com/journal/10.1111/(ISSN)13652354/homepage/ProductInformation.html

European Journal of Oncology Nursing, 2013, 'About the journal', viewed 4 February 2013, from http://www.ejoncologynursing.com/aims

Falkson, G., 1979, 'Mediesonkologie 1979', Curationis,2(3), 48-52. http://dx.doi. org/10.4102/curationis.v2i3.505, PMid:43200

Gakidou, E., Nordhagen, S. \& Obermeyer, Z, 2008, 'Coverage of cervical cance screening in 57 countries: low average levels and large inequalities', PLOS Med, 5(6), e132.

health24, 2013, 'Cancer', viewed 3 June 2013, from http://www.health24.com/ Medical/Cancer

Health SA Gesondheid, 2013, 'Focus and scope' viewed 2 February 2013, http://www. hsag.co.za/index.php/hsag/pages/view/about

Holyoake, D., 2011, 'Is the doctor-nurse game still being played?' viewed 6 April 2013, from http://www.nursingtimes.net/nursing-practice/clinical-zones/ management/is-the-doctor-nurse-game-still-being-played/5037135.article

Indilinga: African Journal of Indigenous Knowledge Systems, 2013, 'About us', viewed 6 February 2013, from http://www.indilinga.org.za/

Issah, F., Maree, J.E. \& Mwinituo, P.P., 2011, 'Expressions of cervical cancer-related signs and symptoms', European Journal of Oncology Nursing, 15(1), 67-72. http:// dx.doi.org/10.1016/j.ejon.2010.06.003, PMid:20673743
Journal of Pain Management, 2013, 'Journal Description', viewed 6 February 2013, from https://www.novapublishers.com/catalog/product_info.php?products id $=6356$

Journal of Research in Nursing, 2013, 'About the journal', viewed 6 February 2013, from http://www.sagepub.com/journals/Journal201720/title

Keogh, J., 1997, 'Professionalization of nursing: development, difficulties and solutions', Journal of Advanced Nursing, 25(2), 302-308. http://dx.doi.org/10.1046/j.13652648.1997.1997025302.x, PMid:9044004

Layne, V., 1998, 'The sound archives at the District Six Museum: a work in progress', viewed 31 March 2013, from http://www.seagullindia.com/archive/chapter10.pdf.

LoBiondo-Wood, G. \& Haber, J., 2010a, 'Integrating the processes of research and evidence-based practice', in LoBiondo-Wood, G. \& Haber, J. (eds.), Nursing research: methods and critical appraisal for evidence-based practice, 7 th edn. pp. 5-26, Mosby, St Louis.

LoBiondo-Wood, G. \& Haber, J., 2010b, 'Nonexperimental designs', in LoBiondoWood, G. \& Haber, J. (eds.), Nursing research: methods and critical appraisal for evidence-based practice, 7th edn., pp. 196-219, Mosby, St Louis

Loubser, H.J. \& Herbst, M.C., 2010, 'Developing a dignity instrument to measure the outcomes of palliative home-based care', Africa Journal of Nursing and Midwifery 12(2), 83-95.

Maboko, E. \& Mavundla, T., 2006, 'The experience of African women diagnosed with both HIV/AIDS and cervical cancer', Africa Journal of Nursing and Midwifery, 8(1), 15-30.

Maree, J.E., 2009, 'An investigation into registered nurse awareness of and practice related to cancer pain', Journal of Pain Management, 3(1), 53-62.

Maree, J.E., 2010, "No condom no sex": easy to say but not possible for all South African women', Health SA Gesondheid, 15(1), Art. \#506, 8 pages. http://dx.doi. org/10.4102/hsag.v15i1.506

Maree, J.E., 2011, 'Yes, breast cancer related lymphoedema can be managed', Health SA Gesondheid, 16(1), Art. \#578, 7 pages. http://dx.doi.org/10.4102/hsag. v16i1.578

Maree, J.E., Combrink, M.J., De Lange, T., Toerien, A.S. \& Bedeker, M., 2011, 'Incidence, severity and management of cancer chemotherapy related oral mucositis in Eastern Cape and Western Cape', Health SA Gesondheid, 17(1), 7 pages. http:// dx.doi.org/10.4102/hsag.v17i1.632

Maree, J.E., Lu, X., Mosalo, A., \& Wright, S.C., 2009, 'Cervical screening in Tshwane, South Africa: women's knowledge of cervical cancer, acceptance of visual inspection with acetic acid (VIA) and practical lessons learnt', Africa Journal of Nursing and

Maree, J.E., Lu, X.M. \& Wright, S.C., 2012, 'Combining breast and cervical screening in an attempt to increase cervical screening uptake. An intervention study in a South an attempt to increase cervical screening uptake. An intervention
African context', European Journal of Cancer Care, 21(1), 78-86.

Maree, J.E., Lu, X.M. \& Wright, S.C., 2012, 'Cervical cancer: South African women's knowledge, lifestyle risks and screening practices', Africa Journal of Nursing and Midwifery, 14(2), 104-115.

Maree, J.E. \& Wright, S.C., 2007, 'Sexual and menstrual practices: risks for cervix cancer', Health SA Gesondheid, 12(3), 55-56. http://dx.doi.org/10.4102/hsag. v12i3.265

Maree, J.E. \& Wright, S.C., 2008, 'Palliative care: a positive outcome for cancer patients?', Curationis, 31(3), 43-49. PMid:19006957

Maree, J. E. \& Wright, S.C., 2010, 'How would early detection be possible? An enquiry into cancer related knowledge, understanding and health seeking behaviour of urban black women in Tshwane, South Africa', European Journal of Oncology Nursing 14(3), 190-196. http://dx.doi.org/10.1016/j.ejon.2009.10.009, PMid:19944646

Maree, J.E. \& Wright, S.C., 2011, 'Cervical cancer: Does our message promote screening? A pilot study in a South African context', European Journal of Oncology Nursing 15(2), 118-123. http://dx.doi.org/10.1016/j.ejon.2010.06.008, PMid:20675189

Maree, J.E., Wright, S.C. \& Makua, T.P., 2011, 'Men's lack of knowledge adds to the cervical cancer burden in South Africa', European Journal of Cancer Care, 20(5), 662-668. http://dx.doi.org/10.1111/j.1365-2354.2011.01250.x, PMid:21501266

Mcilfatrick, S.J. \& Keeney, S., 2003, 'Identifying cancer nursing research priorities using the Delphi technique', Journal of Advanced Nursing, 42(6), 629-636. http://dx.doi. org/10.1046/j.1365-2648.2003.02666.x, PMid:12787236

Mdondolo, N., De Villiers, L. \& Ehlers, V., 2003, 'Cultural factors associated with the management of breast lumps amongst Xhosa women', Health SA Gesondheid, 8(3), 86--97. http://dx.doi.org/10.4102/hsag.v8i3.138

Mojaki, M., Basu, D., Letskokgohka, M. \& Govender, M., 2010, 'Referral steps in district health system are side-stepped', SAMJ, 101(2), 109.

Mokgadi, S. \& Mulaudzi, F.M., 2008, 'The perceptions of traditional healers of cervical cancer care at Ga Mothapo village in Limpopo Province', Indilinga: African Journal of Indigenous Knowledge Systems, 7(1), 103-116.

Molassiotis, A., Gibson, F., Kelly, D., Richardson, A., Dabbour, R., Ahmad, A.M., et al., 2006, 'A systematic review of worldwide cancer nursing research: 1994 to 2003', Cancer Nursing, 29(6), 431-440. http://dx.doi.org/10.1097/00002820200611000-00001, PMid:17135815

Mookeng, M.J., Mavundla, T.R., \& McFarlane, D.M., 2010, 'Barriers to cervical cancer screening within private medical practices in Soshanguve, South Africa', Africa Journal of Nursing and Midwifery, 12(1), 27-38.

Mugivhi, N.H., Maree, J.E. \& Wright, S.C., 2009, 'Rural women's knowledge of prevention and care related to breast cancer', Curationis, 32(2), 38-45. http:// dx.doi.org/10.4102/curationis.v32i2.928

National Health Laboratory Service, 2012, 'Cancer Statistics', viewed 1 June 2013, from http://www.nioh.ac.za/?page=cancer_statistics\&id=163 
Oberholzer, A.E., Nel, E., Myburgh, C.P. \& Poggenpoel, M., 2011, 'Exploring the needs and resources of children in a haematology-oncology unit: original research', Health SA Gesondheid, 16(1). http://dx.doi.org/10.4102/hsag.v16i1.565

O'Cathain, A., Murphy, E. \& Nicholl, J, 2008, 'The quality of mixed methods studies in health services research', Journal of Health Services Research \& Policy, 13(2), 92-98. http://dx.doi.org/10.1258/jhsrp.2007.007074, PMid:18416914

Pearce, S., Kelly, D. \& Stevens, W., 2001, “"More than just money"- widening the understanding of the costs involved in cancer care', Journal of Advanced Nursing, 33(3), 371-379. http://dx.doi.org/10.1046/j.1365-2648.2001.01673.x PMid:11251724,

Reproductive Health Matters, 2013, 'Aims and scope', viewed 14 January 2013, from http://www.journals.elsevier.com/reproductive-health-matters/

Retsas, A., 2000, 'Barriers to using research evidence in nursing practice', Journal of Advanced Nursing, 31(3), 599-606. http://dx.doi.org/10.1046/j.13652648.2000.01315.x, PMid:10718879

Richardson, A., 2004, 'Creating a culture of compassion: developing supportive care for people with cancer', European Journal of Oncology Nursing, 8(4), 293-305. http://dx.doi.org/10.1016/j.ejon.2004.07.004, PMid:15550359

Rwamugira, J. \& Maree, J.E., 2012, 'The findings of a nurse-lead intervention for detection and prevention of oral cancer. A pilot study', European Journal of Cancer Care, 21(2), 266-273. http://dx.doi.org/10.1111/j.1365-2354.2011.01310.x, PMid:22111655
SCIMago, 2007-2013, 'Journal \& Country Rank', viewed 22 May 2013, from http:// www.scimagojr.com

Sibiya, M.N. \& Grainger, L., 2007, 'An assessment of the implementation of the provincial cervical screening programme in selected primary health care clinics in the llembe region, KwaZulu-Natal', Curationis, 30(1), 48-55. http://dx.doi. org/10.4102/curationis.v30i1.1050, PMid:17515316

Sibiya, N. \& Grainger, L., 2010, 'Registered nurses' perceptions of the cervical screening programme in Primary Health Care clinics in the KwaZulu-Natal province of South Africa', Africa Journal of Nursing and Midwifery, 12(1), 15-26.

South African Nursing Council, 1984, 'Regulations relating to the scope of practice of persons who are registered or enrolled under the Nursing Act, 1978', viewed 30 April 2013, from http://www.sanc.co.za/regulat/Reg-scp.htm

South African Statistics, 2012, 'South African Statistics, 2012', viewed 30 April 2013 from http://www.statssa.gov.za/Publications/SAStatistics/SAStatistics2012.pdf

Van Rooyen, D., Le Roux, L. \& Kotzé, W.J., 2008, 'The experiential world of the oncology nurse', Health SA Gesondheid, 13(3), 18-30. http://dx.doi.org/10.4102/hsag. v13i3.283

Van Schalkwyk, S.L., Maree, J.E. \& Wright, S.C., 2008, 'Cervical cancer: the route from signs and symptoms to treatment in South Africa', Reproductive Health Matters, 16(32), 9-17. http://dx.doi.org/10.1016/S0968-8080(08)32399-4 


\section{Appendix 1}

APPENDIX 1: Papers published between 2002 and 2012 included in this review.

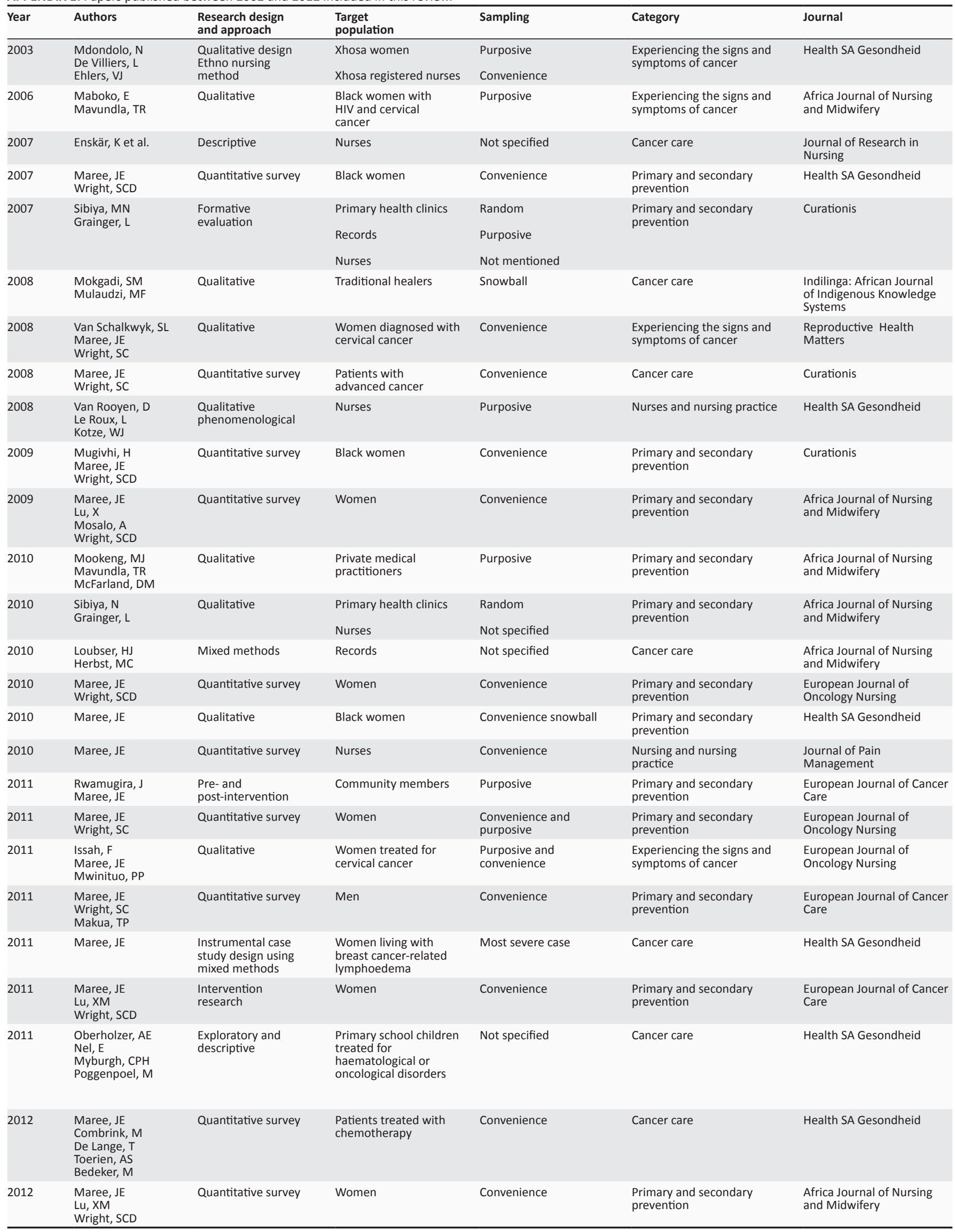

